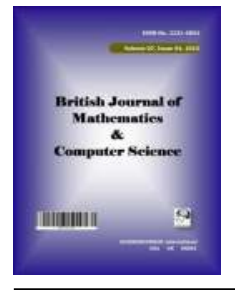

British Journal of Mathematics \& Computer Science

19(3): 1-11, 2016; Article no.BJMCS.29176

ISSN: 2231-0851

SCIENCEDOMAIN international

www.sciencedomain.org

\title{
Modeling Satisfaction Factors that Predict Students Choice of Private Hostels in a Ghanaian Polytechnic
}

\author{
François Mahama $^{1 *}$, Patience Ama Nyantakyiwaa Boahen ${ }^{2}$, \\ Akuamoah Worlanyo Saviour ${ }^{1}$ and John Tumaku ${ }^{1}$
}

${ }^{1}$ Department of Mathematics and Statistics, Ho Polytechnic, P.O.Box HP 217, HO, Ghana.

${ }^{2}$ Takoradi Polytechnic, Ghana.

Authors' contributions

This work was carried out in collaboration between all authors. Author FM designed the study, wrote the protocol and supervised the work. Authors PANB, AWS and JT carried out the statistical analysis.

All authors read and approved the final manuscript.

Article Information

DOI: 10.9734/BJMCS/2016/29176

Editor(s):

(1) Sheng Zhang, Department of Mathematics, Bohai University, Jinzhou, China. Reviewers:

(1) Kikawa Richard Cliff, Tshwane University of Technology, South Africa.

(2) Rachana Pathak, University of Lucknow, Lucknow, Uttar Pradesh, India.

(3) William P. Fox, Naval Postgraduate School, Monterey, USA.

Complete Peer review History: http://www.sciencedomain.org/review-history/16684

Original Research Article

Received: $26^{\text {th }}$ August 2016

Accepted: $17^{\text {th }}$ October 2016

Published: $26^{\text {th }}$ October 2016

\begin{abstract}
The objective of this research was to examine how satisfied students are with the facilities and services provided by private hostels and identify the satisfaction factors that predict student's choice of a hostel. A descriptive, cross-sectional survey was conducted among 350 purposively selected students staying in private hostels in Ho Polytechnic, Ghana. Logistic regression analysis was used to identify the predictors of the satisfaction factors. Results show that five factors "X2 (Security issues of the hostel)", "X4 (Availability of water facilities)", "X5 (Availability of electricity)", "X6 (Calm and peaceful environment)" and "X15 (Availability of toilet facilities)" were statistically significant in the prediction of students' satisfaction with hostel facilities and services with a predicted satisfaction rate of $98.03 \%$. It is therefore recommended that there is a need for private developers to be engaged in a partnership scheme with the school management to construct more hostels on campus with current state of the art facilities which will meet the needs of the growing population of the students. Also, to attract students, management and developers of a hostel should provide an affordable hostel within a calm and peaceful environment with high level of security and availability of water, toilet and electricity facilities.
\end{abstract}

*Corresponding author: E-mail: statisticalmagic@yahoo.com; 
Keywords: Student; hostel; satisfaction; logistic regression.

\title{
DEFINITION OF VARIABLES
}

\author{
X1 : Proximity to lecture halls \\ $X 2$ : Security issues of the hostel \\ X3 : Affordable accommodation fee \\ X4 : Availability of water facilities \\ X5 : Availability of electricity \\ X6 : Calm and peaceful environment \\ X7 : Availability of study area \\ X8 : Proper ventilation system \\ X9 : Availability of a cafeteria \\ X10: Availability of toilet facilities \\ $X 11$ : Availability of recreational facilities \\ $X 12$ : Number of person in a room (Level of privacy) \\ X13 : Availability of waste disposal facilities
}

\section{Introduction}

Sifuna [1], observes that the social demand for higher education is quite high. This has been brought about by the external efficiency that results from higher education. The increased demand for higher education has seen rapid expansion of polytechnic facilities so as to improve access.

In recent years, Ho Polytechnic has experienced phenomenal growth in student numbers which has consequently resulted in high demand for accommodation. Physical planning in the polytechnic has not matched the rate of growth and expansion. The Polytechnic has started running halls of residence on a commercial basis where students pay polytechnic accommodation or look for alternative accommodation.

Students are made to know well in advance that room application is not a guarantee for room allocation. The Polytechnic Private Hostels Coordinating Unit tries to link students who do not get accommodation in the Polytechnic Halls to some private hostels who are registered with the institution. The number of students seeking private accommodation in Ho polytechnic as at 2015 was approximately 1,509.

Although studies have been done to investigate factors influencing residents' satisfaction with their homes and neighbourhood, there seem to be a lack of inquiry into students' satisfaction with their hostel facilities, Amole, [2]. In studies that place the critical lens on students' satisfaction levels of their university accommodation, the units of focus have been diverse such as on the influence of the physical attributes, psychological and management aspects. Most of these studies indicate that there is a direct correlation between the satisfaction levels and the hostel environment. Basically, when the environment meets the individuals' expectation a higher degree of satisfaction has been noted. On the other hand, incongruence between housing needs and aspirations leads to dissatisfaction Mohit et al. [3]. Thus, it can be concluded that understanding students' satisfaction predicting factors can assist tertiary institutions to undertake changes to increase satisfaction among them.

However, the gap for this study is situated on the fact that there is no clear work referencing the students' satisfaction factors that predict choice of hostels in Ghana. Thus this study is aimed towards the development of a better understanding of factors that predict choice of hostels in Ho Polytechnic. Specifically, to establish how satisfied students are with the facilities and services provided by private hostels and determine the factors that predict these satisfactions with hostel facilities and services in Ho Polytechnic. 


\section{Literature}

\subsection{The concept of customer satisfaction}

Gustafsson et al. [4], defined customer satisfaction as a customer's overall evaluation of the performance of an offering to date. This overall satisfaction has a strong positive effect on customer loyalty intentions across a wide range of product and service categories. The satisfaction judgment is related to all the experiences made with a certain business concerning its given products, the sales process, and the after-sale service. Whether the customer is satisfied after purchase also depends on the offer's performance in relation to the customer's expectation. Customers form their expectation from past buying experiences, friends' and associates' advice, and marketers' and competitors' information and promises, Kotler, [5].

In view of Ree et al. [6], customer satisfaction is the degree to which a customer perceives that an individual, firm or organization has effectively provided a product or service that meets the customer's needs in the context in which the customer is aware of and or using the product or service. Satisfaction is not inherent in the individual or the product but is a socially constructed response to the relationship between a customer, the product and the product provider or maker. To the extent that a provider or maker can influence the various dimensions of the relationship, the provider can influence customer satisfaction.

Customer satisfaction is a key factor in the success of any company and is produced when customers' needs have been met and they have derived profit or value from their experience. Also, customer satisfaction brings about new experiences to the customers whose needs have been fulfilled and satisfied. According to Becker et al. [7], customer satisfaction implies an extended relationship through activities such as selling, increasing revenue of the customers, and generating customer maintenance. Mithas et al. [8], mention that customer satisfaction is a factor that directly or indirectly impacts on a company and society. Companies must perform well, adhere to social contracts and show mutual understanding. Customer satisfaction may have an impact either positively or negatively on customer feedback. More satisfaction creates security and decreases loss of clients.

Flint et al. [9], also state that customer satisfaction creates positive word of mouth advertising, attracts more customers to the company, and retains existing customers. Moreover, customer satisfaction creates loyalty as a direct effect. Satisfaction or service quality has been described as an outcome of customers' expectations based on their comparison and perceptions about goods and services and also how the final result transfers to the customers and to what extent it makes them happier Cauruana [10]. Using customer satisfaction, the company can create new relationship circles using its customers and its partners. Furthermore, this characteristic will make the company more reliable.

Mittal et al. [11] have exhibited customer satisfaction to be influencing the factors that signify customer loyalty or in other words, the long-term orientation of a relationship. Furthermore, Geyskens et al. [12] considered customer satisfaction as an essential factor responsible for the long-term association between suppliers and buyers. It has often been enunciated that the affect component of satisfaction could stimulate a satisfied customer to patronize the service provider as well as referring its services to others. The positive effect of customer satisfaction on these dimensions of loyalty has been repeatedly voiced in the literature.

\subsection{Problems with students place of residence}

Handler [13] observes that "every society is faced with the problem of producing human habitation in sufficient quantity, and obtaining the kind of quality desired, at prices that individuals and families can afford". Based apparently on this definition that can be described as a working definition of the ideal residential housing, Handler further indicated that "the problem of housing exists in countries throughout the world". All over the world accommodation hunt is never a thing of the past. There have been stories about freaky flat mate and funny smells. While these are largely urban legends, there are still some shocking and soul comforting student accommodations out there. Ubong [14], had observed that, hostel accommodation 
has not been receiving adequate attention, although it is an important component of pupil personnel management. Residential accommodation available to students is often priced high. For instance, the accommodation fee of Acolatse -Vodzi hall of Ho Polytechnic as at the 2014/2015 academic year was GHC540.00. In 2015/2016 academic year, the accommodation fee increased to GHC630.00 forcing most residents to vacate the hall.

Maintenance at the hall of residence for students is unfortunately poor; the institution has over the years, not been able to keep the hostels in proper residential conditions because of paucity of funds. Akpan [15], declares, "the student population is rapidly increasing, while the infrastructural amenities are declining in supply and their stock depreciating hostel facilities are in deplorable states and are overcrowded".

\subsection{Perception of private accommodation providers}

A study by Reed [6], on the economics of private hostels in Ghana; A case of private hostels on Kumasi Polytechnic campus, investigated the dynamics and benefits of private sector involvement in residential facilities for non-residential students of Kumasi Polytechnic by looking at a financial analysis and social implications of these privately owned hostels and assessed their relationships with major stakeholders. Although the research found that some proprietors of the facilities were termed as "unscrupulous landlords" charging exorbitant rents and exploiting the students, they disputed these allegations and claimed they were not even breaking even with the hostels. The proprietors claimed that some students had immoral behaviour and were like "flocks of sheep without a shepherd" and hence very vulnerable. This study looked at the satisfaction factors of private hostels by Ho Polytechnic students since very limited research on the subject has been done.

Agbenyegah et al. [10], research on residents' perception of off-campus students housing performance in Legon, Ghana was an empirical case study. The purpose of the study was to survey the residential satisfaction of the off- campus students housing in Legon. The study found that residential satisfaction was based on the levels of facilities provided. However, students highlighted that good road facility, car packs, adequate ventilation, crowding and sanitary condition together with delay in responses to maintenance demands as constraints in their hostels. Even though perceptions of private hostels owners of Polytechnic students and management may be important, very few studies have examined these.

\section{Methods and Analytical Tools}

The study employed descriptive, cross-sectional survey design. The setting was the Ho Polytechnic in Volta Region, Ghana. The target population was the students staying in private hostel. A total sample of 350 was taken from the target population. The study employed a non-probabilistic sampling technique, precisely purposive sampling. This sampling technique was used because there is no define structure of students staying in private hostel; hence there is no sampling frame for the population of interest. The study area is constituted by different locations within the study area. These locations of the hostel were considered as strata in the population and respondents were selected purposively. Data for the study was obtained by the administration of a questionnaire. The questionnaire had two sections. The first section consisted of demographic information such as age, and marital status of respondents. The second section dealt with satisfaction factors that predict a student choice of a hostel.

The study makes use of the logistic regression model. Logistic regression is based on binomial probability theory. It is a mathematical modelling approach used in describing the relationship of several independent variables to a dichotomous dependent variable or a limited dependent variable. Binary Logistic regression is a prognostic model that is fitted where there is a dichotomous/binary dependent variable like in this instance where the researcher is interested in whether a student is satisfied, or not. Usually, the categories are coded as " 0 " and " 1 " as it results is a straightforward interpretation. Normally the category of interest also affectionately referred to the case is typically coded as " 1 " and the other group is also known as a "non-case" 
as "0". In this work, student satisfaction, "case", will be denoted by 1 and if a student is dissatisfied "noncase" will be denoted by 0 .

According to Harrell (2001), the formula for a logistic regression model is given by;

$$
\begin{aligned}
& \pi\left(x_{i}\right)=P\left(y_{i}=1: x_{i}\right) \\
& =\left[1+\exp \left(-X^{T} \beta\right)\right]^{-1} \\
& \text { where, } y_{i}=\left\{\begin{array}{c}
1, \text { if a student is satisfied } \\
0, \text { if a student is not satisfied }
\end{array} i=1,2, \ldots, n\right. \\
& X^{T} \beta=\beta_{0}+\beta_{1} x_{1}+\beta_{2} x_{2}+\cdots+\beta_{p-1} x_{p-1} \\
& \beta_{p X 1}=\left[\begin{array}{c}
\beta_{0} \\
\beta_{1} \\
\vdots \\
\cdot \\
\beta_{p-1}
\end{array}\right], \quad X_{p X 1}=\left[\begin{array}{c}
1 \\
X_{1} \\
: \\
\cdot \\
X_{p-1}
\end{array}\right], \quad X_{i p X 1}=\left[\begin{array}{c}
1 \\
X_{i 1} \\
\vdots \\
\cdot \\
X_{i, p-1}
\end{array}\right]
\end{aligned}
$$

where $x_{1}, x_{2}, \ldots, x_{k}$ are independent variables

$\beta_{0}$ is the coefficient of the constant terms

$\beta_{1}, \beta_{2}, \ldots, \beta_{p-1}$ are the coefficient of $p$ independent variables

$\pi\left(x_{i}\right)$ is the probability of an event that depends on $p$ - independent variables

Since $\pi\left(x_{i}\right)=\left[1+\exp \left(-X^{T} \beta\right)\right]^{-1}$

$$
\begin{aligned}
& =\frac{1}{1+\exp \left(-X^{T} \beta\right)} \\
& \Rightarrow 1-\pi\left(x_{i}\right)=\frac{1}{1+\exp (-X \beta)} \\
& =\frac{\left[1+\exp \left(-X^{T} \beta\right)\right]-1}{1+\exp \left(-X^{T} \beta\right)} \\
& =\frac{\exp \left(-X^{T} \beta\right)}{1+\exp \left(-X^{T} \beta\right)} \\
& \Rightarrow \frac{\pi\left(x_{i}\right)}{1-\pi\left(x_{i}\right)}=\left[\exp \left(-X^{T} \beta\right)\right]^{-1} \\
& \text { Thus, } \ln \left(\frac{\pi\left(x_{i}\right)}{1-\pi\left(x_{i}\right)}\right)=\operatorname{logit}\left[\pi\left(x_{i}\right)\right] \\
& =X^{T} \beta
\end{aligned}
$$


Furthermore, Kutner et al. (2005) stated that since the dependent variable is dependent and can take values 1 and 0 with probabilities $\pi\left(x_{i}\right)$ and $1-\pi\left(x_{i}\right)$ respectively, $\mathrm{Y}$ follows a Bernoulli distribution with $(Y)=$ $\pi\left(x_{i}\right)$.

$$
\begin{aligned}
& \text { Thus, } Y_{i}=\pi\left(x_{i}\right)+\varepsilon_{i} \\
& E\left(Y_{i}\right)=\pi\left(x_{i}\right) \\
& =\left[1+\exp \left(-X^{T} \beta\right)\right]^{-1} \\
& =\frac{1}{1+\exp \left(-X^{T} \beta\right)} \\
& P\left(Y_{i}=1\right)=\pi\left(x_{i}\right) \\
& P\left(Y_{i}=0\right)=1-\pi\left(x_{i}\right)
\end{aligned}
$$

The probability density function can be presented as

$$
f_{i}\left(Y_{i}\right)=\pi\left(x_{i}\right)^{Y_{i}}\left[1-\pi\left(x_{i}\right)\right]^{1-Y_{i}}, \quad \text { for } Y_{i}=0,1,2, \ldots, n
$$

The $Y_{i}$ 's are assumed to be independent and thus, the joint probability function is given by

$$
\begin{aligned}
& g\left(Y_{1}, \ldots, Y_{n}\right)=l(\beta)=\prod_{i=1}^{n} f_{1}\left(Y_{i}\right) \\
& =\prod_{i=1}^{n} \pi\left(x_{i}\right)^{Y_{i}}\left[1-\pi\left(x_{i}\right)\right]^{1-Y_{i}}
\end{aligned}
$$

where $\beta$ is a vector of unknown parameters.

\section{Results and Analysis}

A total of 350 students staying in the private hostel completed the questionnaire on satisfaction factors that predict student's choice of hostel. Table 1 summarizes the socio-demographic information of the respondents. From the Table 1, 172 of the respondents representing $49.1 \%$ were males whereas 178 representing $50.9 \%$ were females; in which majority of people who responded to this questionnaire are between 18 and 25 , followed by 26 and 35 . This means that close to $83.7 \%(52.6+31.1)$ of the time, views leading to conclusions drawn from this research could be attributed largely to students of that age group. The analysis further indicated that out of the total 350 respondents, majority of them which represent $76 \%$ were single whiles the rest $24 \%$ were married.

Fig. 1 shows how satisfied students are with the facilities and services provided by the hostel in which about 53 of the respondents indicated that they are highly satisfied, 123 were satisfied, 43 were neutral, 101 were dissatisfied and finally, 30 of them were highly dissatisfied.

Table 2 gives the information about the contribution or importance of each predictor variables. The test that is used here is known as the Wald test and the test statistic for each predictor variable is shown in the column labelled Wald. The significance of the Wald statistic for each independent variable indicates the overall factors predicting students' satisfaction with hostel facilities and services $(P<0.05)$. The significance of the variables is assessed by the p-value (represented in the table by "sig."), the Wald's statistic value or the odd ratios represented by $\operatorname{Exp}(\beta)$. 


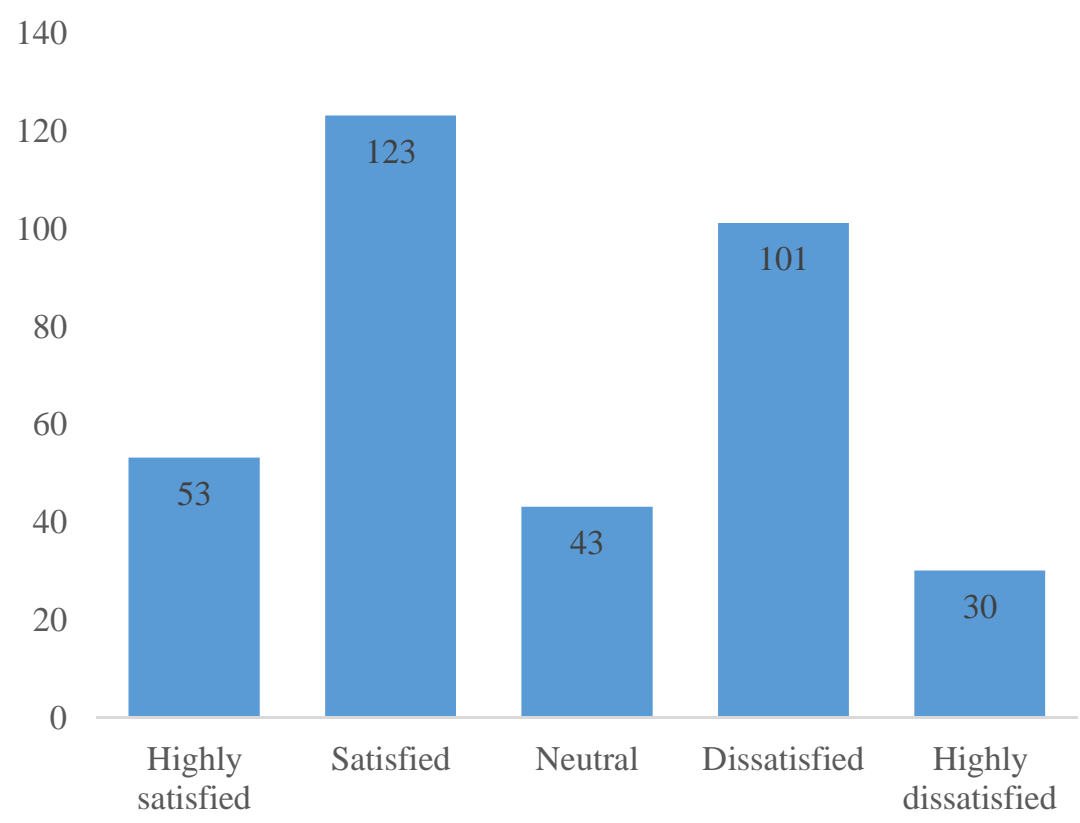

Fig. 1. Respondents satisfaction with hostel facilities and services

Table 1. Demographic information of the participants $(n=350)$

\begin{tabular}{lll}
\hline Variables & Frequency & Percentage \\
\hline Gender & 172 & 49.1 \\
Male & 178 & 50.9 \\
Female & & \\
Age & 184 & 52.6 \\
$18-25$ & 109 & 31.1 \\
$26-35$ & 45 & 12.9 \\
$36-45$ & 12 & 3.4 \\
$46-56$ & & 76.0 \\
Marital status & 266 & 24.0 \\
Never married & 84 & \\
Married & Source: Field data, 2016
\end{tabular}

From the table, the Wald statistics and the significance level shows that 5 out of the 13 independent variables namely; "X2 (Security issues of the hostel)", "X4 (Availability of water facilities)", "X5 (Availability of electricity)", "X6 (Calm and peaceful environment)" and "X15 (Availability of toilet facilities)" were significant to the prediction of satisfaction with hostel facilities and services. This is because they had pvalues of less than 0.05 (sig. in Table 2).

Thus the logistic function is given by the equation below:

$$
\text { In } \frac{\pi\left(x_{i}\right)}{1-\pi\left(x_{i}\right)} 5.033-0.737 X 2+0.755 X 4-0.845 X 5-0.980 X 6+0.683 X 10
$$

Where $X 2$ is Security issues of the hostel, $X 4$ is Availability of water facilities, $X 5$ is Availability of electricity, $X 6$ is Calm and peaceful environment and X15 is Availability of toilet facilities. 
Table 2. Logistic regression estimates of factors that predict student's satisfaction with hostel facilities and service

\begin{tabular}{|c|c|c|c|c|c|c|c|c|}
\hline & \multirow[t]{2}{*}{ B } & \multirow[t]{2}{*}{ S.E. } & \multirow[t]{2}{*}{ Wald } & \multirow[t]{2}{*}{ df } & \multirow[t]{2}{*}{ Sig. } & \multirow[t]{2}{*}{$\operatorname{Exp}(B)$} & \multicolumn{2}{|c|}{$95 \%$ C.I. for $\operatorname{EXP}(B)$} \\
\hline & & & & & & & Lower & Upper \\
\hline $\mathrm{X} 1$ & -0.037 & 0.255 & 0.021 & 1 & 0.886 & 0.964 & 0.584 & 1.590 \\
\hline $\mathrm{X} 2$ & -0.737 & 0.211 & 12.247 & 1 & 0.000 & 0.479 & 0.570 & 1.108 \\
\hline $\mathrm{X} 3$ & -0.230 & 0.169 & 1.838 & 1 & 0.175 & 0.479 & 0.317 & 0.723 \\
\hline X4 & 0.755 & 0.258 & 8.542 & 1 & 0.003 & 2.128 & 1.282 & 3.531 \\
\hline X5 & -0.845 & 0.197 & 18.348 & 1 & 0.000 & 0.430 & 0.292 & 0.632 \\
\hline X6 & -0.980 & 0.255 & 14.735 & 1 & 0.000 & 2.665 & 1.616 & 4.396 \\
\hline $\mathrm{X} 7$ & -0.107 & 0.205 & 0.274 & 1 & 0.600 & 1.981 & 1.093 & 3.588 \\
\hline $\mathrm{X} 8$ & 0.386 & 0.356 & 1.177 & 1 & 0.278 & 1.471 & 0.732 & 2.955 \\
\hline X9 & -0.049 & 0.264 & 0.035 & 1 & 0.852 & 0.952 & 0.567 & 1.598 \\
\hline X10 & 0.683 & 0.303 & 5.083 & 1 & 0.024 & 0.898 & 0.601 & 1.342 \\
\hline $\mathrm{X} 11$ & -0.473 & 0.333 & 2.021 & 1 & 0.155 & 0.623 & 0.324 & 1.196 \\
\hline $\mathrm{X} 12$ & -0.058 & 0.241 & 0.058 & 1 & 0.809 & 0.943 & 0.588 & 1.514 \\
\hline X13 & 0.108 & 0.239 & 0.204 & 1 & 0.652 & 1.114 & 0.698 & 1.777 \\
\hline Constant & 5.033 & 2.499 & 4.055 & 1 & 0.044 & 0.007 & & \\
\hline
\end{tabular}

Source: Field data, 2016

Furthermore, the odd ratio $(\operatorname{Exp}(\beta))$ for the significant factors, shows the increase (or decrease if the ratio is less than one) in odds of being in one outcome category (satisfied or not satisfied) when the value of the predictor increases by one unit. From Table 2, the odds or risk of a student being satisfied, is 0.479 for $X 2$ (Security issues of the hostel). This indicates that, the risk of a student being satisfied is 0.479 times higher for a student who perceived a hostel to be highly secured, all other factors being equal. For X4 (Availability of water facilities), the odd ratio of 2.128 indicates that risk of a student having satisfaction with a hostel having water facilities, is 2.128 times more likely to derived satisfaction as compared with those not having water facilities, all other factors being equal. For X5 (Availability of electricity), the odd ratio of 0.430 indicates that the risk of a student deriving satisfaction is 0.430 times higher for a student who has availability of electricity in their hostel than for a student who does not have access to electricity in their hostel, all other factors being equal.

Furthermore, for X6 (Calm and peaceful environment), the odd ratio of 2.665 indicated that the risk of a student deriving satisfaction is 2.665 times higher for a student who has a calm and peaceful environment in their hostel, all other factors being equal. Finally, the odd ratio of 0.898 for X15 (Availability of toilet facilities) indicates that, for any hostel with toilet facilities, the risk of getting satisfaction increases by a factor of 0.898 , all other factors being equal.

The next output table seeks to rank five (5) attributes that influence students' most based on their choice of a hostel. The attributes were ranked by students on a scale of $1-5$, with 1 being the least important and 5 the most important. The order in which students ranked the attributes came out as shown in Table 3. (Note: Mean importance is calculated with the values of 1 for least important and 5 for most important. Hence, a higher mean indicates a greater importance).

Table 3 shows the various mean ranks of respondents on the factors that influence their choice of a hostel the most. It can be seen that "accommodation charges" recorded the highest mean, followed by "security issues"; "availability of water and electricity"; "proximity to lecture halls" and "level of privacy" in that order.

The next output table shows whether or not students differentiate between these various hostel choice attributes. 
Table 3. Relative importance rankings by students for hostel choice attribute

\begin{tabular}{ll}
\hline & Mean rank \\
\hline Security issues & 3.15 \\
Availability of water and electricity & 3.07 \\
Level of privacy & 2.66 \\
Proximity to lecture halls & 2.73 \\
Accommodation charges & 3.39 \\
\hline
\end{tabular}

Source: Field data, 2016

Table 4. Kendall's co-efficient of concordance for hostel choice attribute

\begin{tabular}{ll}
\hline Test statistics & \\
\hline Kendall's W & 0.040 \\
Chi-square & 55.329 \\
Df & 4 \\
Asymp. significance & 0.000 \\
\hline
\end{tabular}

Source: Field data, 2016

The Kendall's Co-efficient of Concordance (W) for the rankings of hostel choice attributes as shown in table 4 above is 0.040 . This means that the degree of agreement on a zero to one scale is 0.040 . The degree of unanimity as measured by the $\mathrm{W}$-statistics is about $4 \%$ since the score is zero for random ranking and 1 for perfectly unanimous ranking. Thus, to a large extent, there is agreement among respondents with regards to the rankings provided. The asymptotic distribution gave a significance level value of 0.000 , which is less than 0.05 . Thus, the null hypothesis (the rankings disagree) is rejected and the alternative hypothesis (the rankings agree) is accepted.

Thus students in the study area can therefore, be said to generally agree that the most important attributes of hostel choice are more related first to accommodation charges, secondly to security issues, followed by availability of water and electricity, proximity to lecture halls, with level of privacy been the least important attribute.

\section{Conclusion and Recommendation}

Concerning how satisfied students are with the facilities and services of a hostel, about 53 of the respondents indicated that they are highly satisfied, 123 were satisfied, 43 were neutral, whiles 101 were dissatisfied and finally, 30 of them were highly dissatisfied.

Furthermore, the study revealed that five (5) factors; "X2 (Security issues of the hostel)", "X4 (Availability of water facilities)", "X5 (Availability of electricity)", "X6 (Calm and peaceful environment)" and "X15 (Availability of toilet facilities)" were statistically significant in the prediction of students' satisfaction with hostel facilities and services with a predicted satisfaction rate of $98.03 \%$. This indicates that there is a probability that $98.03 \%$ of students will be satisfied with hostel facilities and services based on the given characteristics, all other things being equal.

Finally, students in the study area generally agree that the most important attributes of hostel choice are more related first to accommodation charges, secondly to security issues, followed by availability of water and electricity, proximity to lecture halls, with level of privacy being the least important attribute.

It is therefore recommended that there is a need for private developers to be engaged in a partnership scheme with the school management to construct more hostels on campus with current state of the art facilities which will meet the needs of the growing population of the students. Also, to attract students, management 
and developers of a hostel should provide an affordable hostel within a calm and peaceful environment with high level of security and availability of water, toilet and electricity facilities.

Finally, potential stakeholders in the design, construction and management of hostel facilities should consider factors such as accommodation charges, secondly security issues, followed by availability of water and electricity, and proximity to lecture halls when putting up a hostel in order to attract students.

\section{Competing Interests}

Authors have declared that no competing interests exist.

\section{References}

[1] Sifuna D. The governance of Kenyan public universities. Nairobi: Lyceum Educational Consultants Limited; 2006.

[2] Amole D. Residential satisfaction in students' housing. Journal of Environmental Psychology. 2009;29(1):76-85.

[3] Mohit MA, Ibrahim M, Rashid YR. Assessment of residential satisfaction in newly designed public low-cost housing in Kuala Lumpur, Malaysia. Habitat International. 2010;34(1):18-27.

[4] Gustafsson A, Johnson M, Roos J. The effects of customer satisfaction, relationship commitment dimensions and triggers on customer retention. American Marketing Association. 2005;1547-7185.

[5] Kotler P. Marketing management. Pearson Education, Inc. Fifth Edition; 2003.

[6] Reed JH, Hall NP. Methods for measuring customer satisfaction. Energy Evaluation Conference. Chicago; 1997.

[7] Becker J, Greve G, Albers S. The impact of technological and organizational implementation of CRM on customer acquisition, maintenance, and retention. International Journal of Research in Marketing. 2009;26:207-215.

[8] Mithas S, Krishnan M, Fornell C. Why do customer relationship management applications affect customer satisfaction? Journal of Marketing. 2005;69:201-209.

[9] Flint D, Blocker C, Boutin P. Customer value anticipation, customer satisfaction and loyalty: An empirical examination. Industrial Marketing Management. 2011;40:219-230.

[10] Caruana A. Service loyalty: The effects of service quality and the mediating role of customer satisfaction. European Journal of Marketing. 2002;36:811-828.

[11] Mittal V, Kamakura W. Satisfaction, repurchase intent, and repurchase behavior: Investigating the moderating effects of customer characteristics. Journal of Marketing Research. 2001;38(1):131-142.

[12] Geyskens I, Steenkamp J, Kumar N. Generalizations about trust in marketing channel relationships using meta-analysis. International Journal of Research in Marketing. 1999;15(3):223-248.

[13] Handler AB. Housing. In C. M. Cummings (Ed.). Encyclopedia Americana. Danbury, Connecticut: Grolier Inc. 2001;14:482. 
[14] Ubong B. Hostel accommodation in tertiary educational institutions in Nigeria: To be or not to be; 2007.

(Retrieved July, 28, 2009)

[15] Akpan G. E. The effect of student income support on academic performance. The Nigerian Journal of Economic and Social Studies; 1998.

() 2016 Mahama et al.; This is an Open Access article distributed under the terms of the Creative Commons Attribution License (http://creativecommons.org/licenses/by/4.0), which permits unrestricted use, distribution, and reproduction in any medium, provided the original work is properly cited.

Peer-review history:

The peer review history for this paper can be accessed here (Please copy paste the total link in your

browser address bar)

http://sciencedomain.org/review-history/16684 